\title{
Mudanças conceituais (ou cognitivas) na educação em ciências: revisão crítica e novas direções para a pesquisa
}

\author{
Orlando Aguiar Jr. ${ }^{1[1]}$
}

\section{Resumo}

Diante do desafio de consolidar e aprofundar as pesquisas no campo da educação em ciências, coloca-se a necessidade de se fazer um balanço crítico das pesquisas realizadas nos últimos vinte anos em torno do problema da "mudança conceitual". Essa revisão abrange dois aspectos, a nosso ver complementares: 1. Qual é o sentido e alcance das mudanças que acompanham as aprendizagens em ciências; 2. Qual é o vetor epistemológico da mudança. Reconhecendo a diversidade de abordagens e referenciais teóricos a que se submeteu o tema, procuramos destacar as principais contribuições e os novos desafios colocados à pesquisa e à prática educativa.

\section{Introdução}

O tema da promoção de mudanças acompanha, normalmente, os debates em torno de projetos educativos, não apenas no plano social, mas também no nível dos indivíduos. De fato, a educação pode ser entendida como ação capaz de desencadear mudanças nos sujeitos educandos, visando equipar as novas gerações de um conjunto de valores, competências e conhecimentos que os habilitem a exercer plenamente a condição de sujeitos criativos nos marcos da cultura e da sociedade de que fazem parte.

$\mathrm{Na}$ educação em ciências, os modelos de ensino voltados para a promoção de mudanças são relativamente recentes, o que pode ser explicado pela forte influência positivista em todos os âmbitos de organização e gestão do ensino. Essa perspectiva conduziu a uma visão dos processos de aprendizagem em ciências como resultado de associação gradativa e seqüencial de informações, que nada teria a ver com as formas primitivas de entendimento das crianças.

Esse quadro altera-se profundamente a partir do final da década de 70, quando se passou a considerar seriamente a influência das idéias e noções prévias dos estudantes na apropriação de conceitos e teorias científicas. A pesquisa em educação em ciências, inspirada por estudos construtivistas no campo da filosofia das ciências e da psicologia do desenvolvimento cognitivo, obteve um amplo repertório de conhecimentos sobre as concepções dos estudantes, o que levou a conceber os processos de aprendizagem em ciências como resultado de "mudanças conceituais". Desde então, vários estudos foram realizados, visando não apenas precisar o sentido das mudanças almejadas, como também destacar condições para sua ocorrência. $O$ relativo fracasso de iniciativas destinadas a promover a mudança conceitual em sala de aula conduziu a um amadurecimento desse campo de pesquisa, com o levantamento de novas questões para investigação, a busca de fundamentos teóricos mais

${ }^{1[1]}$ Faculdade de Educação da UFMG - orlando@fae.ufmg.br 
adequados e a proposição de modelos diversos para lidar com a complexidade dos processos de aprendizagem escolar.

Um exame crítico dessa produção é condição para o estabelecimento de um programa progressivo de pesquisas no campo da educação em ciências, que retire lições dos estudos já realizados e construa uma agenda de questões renovadas para a investigação futura. Nessa revisão, iremos tratar de dois elementos fundamentais. Em primeiro lugar, convém ressaltar as diversas posições quanto à natureza dos processos de mudança que acompanham a aprendizagem em ciências. A abrangência dos fatores e aspectos destacados nesses estudos permitem considerar a expressão "mudança conceitual" insuficiente e restritiva para o atual estado de conhecimentos na área.

Num segundo eixo da revisão, destacamos os estudos que consideram a questão da progressão dos níveis de entendimento dos estudantes, com a proposição de "formas intermediárias" entre os níveis de partida dos estudantes e as metas de aprendizagem da educação em ciências. A busca de um vetor epistemológico em direção do qual se situam as mudanças necessárias à aprendizagem em ciências constitui um desafio à pesquisa com importantes desdobramentos para a construção de currículos, o planejamento do ensino e a avaliação da aprendizagem em ciências.

\section{Sobre a natureza das mudanças}

Grosso modo, podem-se dividir os trabalhos em duas categorias, segundo a preocupação e a abordagem predominante - epistemológica ou psicológica. Os primeiros consistem em propor modelos para mudanças conceituais inspirados em trabalhos derivados da filosofia das ciências, ou seja, em projetar para a educação científica desafios semelhantes àqueles enfrentados historicamente pelas comunidades científicas quando do debate entre teorias rivais em um dado domínio do conhecimento. O segundo grupo de estudos insere-se no campo da psicologia cognitiva, no sentido de precisar o modo como as crianças pensam e os fatores que determinam ou favorecem mudanças ao longo de seu desenvolvimento e no curso da aprendizagem escolar em domínios específicos do conhecimento. Embora o olhar para a mudança seja distinto, quer se considere a perspectiva filosófica ou psicológica, não há, tampouco, consenso sobre a natureza das mudanças no interior de cada uma dessas abordagens.

\subsection{Abordagens predominantemente epistemológicas}

Os trabalhos inspirados em perspectivas epistemológicas sobre a natureza das mudanças divergem entre si não apenas pela pluralidade de tratamentos que o tema tem recebido na filosofia da ciência, mas ainda pelas implicações desses estudos ao contexto da aprendizagem escolar. Um dos primeiros trabalhos a estabelecer uma teoria para mudanças conceituais nas aprendizagens em ciências foi proposto pelo grupo da Universidade de Cornell (POSNER, STRIKE, HEWSON \& GERTZOG, 1982). O trabalho fundamenta-se na análise epistemológica do problema da mudança científica, inspirado em estudos histórico-filosóficos de Thomas Kuhn, Imre Lakatos e Stephan Toulmin. O ponto básico do "modelo de mudança conceitual" proposto por Posner e colaboradores consiste em afirmar o caráter racional das 
aprendizagens, isto é, em supor que aprender é tornar-se capaz de compreender e aceitar idéias, compondo-as com suas concepções anteriores, quando compatíveis, ou escolhendo entre concepções mutuamente inconsistentes, quando isso se mostrar necessário. O modelo volta-se para as mudanças radicais, semelhantes àquelas que acompanham as revoluções científicas, no sentido kuhniano. Dois componentes básicos são propostos: a ecologia conceitual e as condições para que as mudanças ocorram. A ecologia conceitual é constituída por elementos que organizam, selecionam ou impedem o avanço do conhecimento do sujeito, sendo composta por anomalias, compromissos epistemológicos e crenças metafísicas. Quanto às condições para mudanças, estas decorrem de uma avaliação por parte do sujeito da aprendizagem quanto à plausibilidade, inteligibilidade e poder explicativo das novas concepções, assim como de uma certa insatisfação quanto às concepções anteriores. $O$ modelo de mudança conceitual proposto por esses autores foi extensamente utilizado, mas sofreu severas críticas por sua excessiva simplificação, sendo considerado, por muitos, como sendo incapaz de apreender a complexidade dos processos de aprendizagem escolar em ciências.

Em trabalhos posteriores, os autores introduziram alguns refinamentos importantes no modelo original. HEWSON (1985) destaca a importância de atuar explicitamente sobre os compromissos epistemológicos dos estudantes, visando aumentar as exigências de generalidade e consistência interna, essenciais ao desenvolvimento de sistemas teóricos na ciência, mas de menor relevância para o pensamento espontâneo. Esse autor introduz, ainda, a noção de status das concepções envolvidas (HEWSON \& THORLEY, 1989), considerando-as como uma avaliação pessoal do aprendiz acerca de sua plausibilidade, inteligibilidade e poder explicativo, ou seja, se o sujeito compreende, aceita e considera úteis as idéias novas e antigas e, também, se as considera satisfatórias. Nesse sentido, a mudança conceitual não envolveria escolha de idéias rivais, mas o aumento ou a diminuição do status das concepções com base nos elementos presentes na ecologia conceitual. Como veremos, essa abordagem antecipa uma visão mais pluralista dos modos de entendimento possíveis de serem postos em evidência pelo sujeito da aprendizagem quando da análise de fenômenos naturais ou tecnológicos.

STRIKE \& POSNER (1992), em sua revisão do modelo original de mudança conceitual, procuram examinar variáveis próprias do contexto escolar de aprendizagem, o que conduz a uma postura mais cautelosa em relação às analogias entre as mudanças conceituais em sala de aula e os estudos acerca das revoluções científicas na história do pensamento científico. Os autores propõem que outros fatores devem ser levados em conta na descrição da ecologia conceitual, a fim de se incluírem motivos e metas dos aprendizes, o que seria, em grande medida, decorrente de fatores institucionais e sociais próprios do ambiente escolar. Consideram, ainda, necessário considerar, de modo dinâmico, interativo e evolutivo, as concepções dos estudantes assim como os elementos que compõem sua ecologia conceitual.

Outros autores (VILLLANI,1992; DUSCHL \& GITOMER, 1991) partem de estudos de filosofia da ciência de LAUDAN (1984) para afirmar o caráter gradual e evolucionário das mudanças conceituais, em oposição à imagem de mudanças radicais sugeridas a partir de uma perspectiva kuhniana ou lakatosiana desses processos (KUHN, 1975; LAKATOS, 1979). Cauteloso em relação às transposições dos trabalhos da filosofia das ciências para a compreensão dos processos de aprendizagem em sala de aula, VILLANI (1992) procura 
destacar, nesses trabalhos, elementos reveladores das resistências dos estudantes a mudanças. Como Laudan, o autor considera que as mudanças mais profundas na ciência envolvem diferentes compromissos com a ontologia, a metodologia, a direção e os valores das "tradições de pesquisa" e, apenas indiretamente, com suas teorias. Conclui, então, que a aprendizagem efetiva em ciências não envolve apenas mudanças nos conceitos, mas sobretudo na natureza das questões formuladas, nas entidades básicas envolvidas, nos métodos e na direção a ser perseguida na aprendizagem. O processo de mudança apresentaria, assim, uma fase inicial e exploratória, em que se perseguem novos modelos e se checam novas idéias e teorias, sem que isso conduza a um abandono de idéias anteriores. Segundo o autor, a aprendizagem efetiva e duradoura em ciências envolve um processo lento de mudanças que deve dirigir-se não apenas para a assimilação de conceitos em um dado campo, quanto para novos modos de raciocínio, demandas epistemológicas e valores cognitivos.

DUSCHL \& GITOMER (1991) destacam a crítica, desenvolvida por LAUDAN (1984), ao "modelo holístico da mudança". Segundo Laudan, as mudanças científicas são decorrentes de reestruturações "não simultâneas nem hierárquicas" na ontologia - referente à natureza do objeto do conhecimento -, na metodologia - colocação do problema de investigação e formas de abordagem - e na axiologia - valores e metas a serem perseguidos. A partir dessa formulação, Duschl e Gitomer consideram que princípios, leis e teorias científicas devem ser ensinados juntamente com o conhecimento estratégico do domínio, ou seja, aquele conhecimento envolvido na avaliação da teoria e na organização de evidências, observações e dados. Como estratégia de ensino, propõem o uso da "cultura do portifólio", em que os estudantes passam a se responsabilizar, juntamente com os professores, pela avaliação e regulação de sua própria aprendizagem.

O trabalho de NERSESSIAN $(1987,1992)$ encontra-se a meio caminho entre a perspectiva epistemológica, realizada através de um rigoroso exame de episódios da história da física, e a abordagem psicológica, revelada por processos cognitivos que a autora procura destacar a partir da análise desses episódios. Assim, a história da ciência é vista pela autora "como um repositório de conhecimentos sobre como prosseguir construindo, modificando e comunicando representações científicas" (1992: 54). Ao acompanhar, por exemplo, a evolução do conceito de campo na física, de Faraday a Einstein, a autora afirma que seu significado, muito mais do que uma definição precisa, comporta múltiplos componentes, tais como estrutura matemática, propriedades causais, status ontológico e referência a outros conceitos. Além disso, a dinâmica do processo histórico revela, na visão da autora, mudanças graduais, em que os conceitos são formados por combinação, diferenciação e transferências entre aqueles já existentes. O estudo dos períodos de transição que antecedem as grandes "revoluções" conceituais na física permitiu, à autora, destacar o desenvolvimento e uso de certos procedimentos heurísticos específicos: analogias, experiências de pensamento, análise de casos-limite e raciocínio apoiado em representações imagísticas. Para Nersessian, a aprendizagem em ciências envolve aprender a manejar essas técnicas de abstração, em detrimento de considerações acerca da consistência formal dos argumentos, que cumprem, a seu ver, papel pouco relevante nos momentos de mudança. 
Essa breve panorâmica nos mostra a complexificação dos modelos e estudos desenvolvidos e o afastamento progressivo do modelo "ingênuo" da mudança radical e definitiva. Pelo contrário, os estudos revelam tensões entre elementos de continuidades e rupturas nos processos de mudança, tanto na história da ciência quanto nas salas de aula. Além disso, as comparações entre as condutas de comunidades científicas e as condutas de estudantes em situações de aprendizagem escolar passam a ser consideradas a partir das práticas sociais desses grupos, evidenciando suas diferenças em termos de propósitos e contextos.

\subsection{Abordagens predominantemente psicológicas}

A panorâmica da pesquisa se diversifica ainda mais quando se consideram as dimensões psicológicas dos processos de aprendizagem em sala de aula. Nesse sentido, muitos aspectos podem ser examinados: a natureza dos conceitos científicos e das concepções dos estudantes, os fatores considerados centrais nas mudanças, a tensão entre as dimensões sociais e individuais, as variáveis de contexto e seu papel na aprendizagem, entre outros.

Ao examinar o objeto das mudanças projetadas pela educação em ciências, Dı SESSA (1998) critica a imprecisão teórica do que sejam conceitos. Segundo o autor, o problema central das mudanças conceituais reside em modos de ver e pensar o mundo. Propõe que os conceitos sejam tomados como "classes de coordenação" (cordination classes), que o autor define como "conjunto complexo de modos que as pessoas utilizam para ler classes particulares de informações sobre o mundo" (DI SESSA, 1998: 1188). Isso inclui a utilização de estratégias de atenção dirigida e integração das observações relevantes para se obter informações sobre um dado aspecto da realidade. Além dessas "estratégias de leitura", as classes de coordenações contêm um componente causal, que permite deduzir resultados a partir de determinadas condições ou, ainda, observar resultados e inferir as precondições dadas. No entanto o autor não considera que as concepções dos estudantes compartilhem propriedades de teorias. Em lugar disso, constituem "primitivos fenomenológicos" (phenomenological primitives, ou p-prims), ou seja, guardam relações diretas com fenômenos e têm caráter generativo, como espécies de exemplares que dirigem a ação nas instâncias da vida cotidiana. Na medida em que a causalidade física dessas representações é rica e diversa, a invariância das mesmas torna-se problemática, o que explica a dependência dos seus conceitos aos contextos em que se manifestam. Entretanto, os p-prims não constituem, individualmente, classses de coordenações, pois seriam muito pontuais e isolados para tanto: “... se existem classes de coordenação ingênuas, sem dúvida múltiplos p-prims estão envolvidos na rede causal, mas não são adequadamente considerados como conceitos em si” (DISESSA, 1998: 1179).

A posição de diSessa se contrapõe a uma visão de que as concepções dos estudantes são fortemente estruturadas, à maneira de "teorias" ou "paradigmas". O embate entre essas duas correntes é expressão da tensão entre elementos de estabilidade e mobilidade indicados pelos resultados das pesquisas empíricas em aprendizagem em ciências. NIEDDERER \& SCHECKER (1992) consideram que, para lidar com esses dois aspectos, seja necessário distinguir, nos sistemas cognitivos, as construções atuais (current constructions) e os elementos estáveis de uma estrutura profunda (deep structure). Embora afirmem não haver limites bem estabelecidos entre representações mentais e processos cognitivos, os autores apresentam um 
modelo em que se alternam movimentos de "pensamento" (thinking) - em que os elementos já existentes no sistema cognitivo são aplicados a uma nova situação - e de "aprendizagem" (learning) - em que se verificam mudanças resultantes de um processo de desenvolvimento do sistema ao interagir com situações externas. As mudanças cognitivas assim preconizadas envolveriam elementos de natureza diversa, tais como redes semânticas, concepções, esquemas cognitivos gerais, demandas e valores cognitivos, elementos causais, formas de pensamento, entre outros. Niedderer e Schecker afirmam, ainda, que o processo de mudança é sujeito a flutuações, em que idéias concorrentes se alternam, e que a nova concepção apenas lentamente ganha força.

VOSNIADOU (1994) desenvolve um modelo que, do mesmo modo, procura conciliar elementos de estabilidade e mobilidade aos processos cognitivos. A autora sugere que, entre as teorias científicas e as teorias específicas dos estudantes acerca do mundo natural, existe uma incompatibilidade decorrente de certos pressupostos epistemológicos e ontológicos que formam a base do sistema de crença dos alunos. Essas bases da física intuitiva são estabelecidas precocemente na infância e constituem o que a autora denomina framework theory (que iremos designar como teoria de base). A teoria de base seria fundamentalmente restritiva, atuando no sentido de dirigir os modos como os sujeitos interpretam suas observações e as informações que recebem da cultura, de modo a construir teorias específicas sobre o mundo físico. Segundo Vosniadou, as teorias específicas são continuamente enriquecidas e modificadas ao longo das interações dos indivíduos com a cultura, enquanto a teoria de base apresenta uma maior resistência às mudanças, sendo freqüente e recorrentemente utilizadas quando o sujeito procura interpretar novas situações. A autora apresenta estudos sobre concepções da Terra como corpo cósmico, ciclos de dias e noites, concepções de força e de calor, interpretando-os como tentativas dos estudantes em reconciliar seus modelos físicos com os modelos culturalmente aceitos, de modo a preservar, entretanto, algumas restrições de suas teorias de base. A partir desses estudos, Vosniadou destaca os elementos que fazem parte da teoria de base (pressupostos ontológicos e epistemológicos), assim como as crenças e modelos mentais que constituem as teorias de domínio específico. A autora conclui afirmando ser o processo de mudança conceitual resultado de revisão gradual dos pressupostos e crenças tanto nas teorias específicas quanto nas teorias de base.

Em outro estudo, VOSNIADOU \& IOANNIDES (1998: 1222) afirmam que o processo de mudança conceitual "envolve não apenas mudanças em crenças e pressuposições específicas, mas também requer o desenvolvimento de uma consciência metaconceitual e a construção de estruturas teóricas com maiores sistematicidade, coerência e poder explanatório". As autoras consideram que as estratégias e intervenções do ensino devem tornar os estudantes conscientes tanto de suas representações implícitas, quanto das crenças e pressupostos que restringem seu avanço. Destacam que as crianças e jovens aprendizes são bons formuladores de teorias, mas não costumam considerar suas explicações como hipóteses a serem examinadas racionalmente. Desse modo, as atividades de ensino devem incentivar os estudantes a explicitar suas representações e crenças, a justificá-las junto aos seus pares e professores, a compreender suas limitações e a buscar sua superação. Consideram ainda 
necessário compreender como os sistemas simbólicos, produtos culturais, são internalizados e influenciam nos processos de pensamento.

O pressuposto de Vosniadou, segundo o qual um número limitado de progressos decisivos é fundamental na aprendizagem em ciências é compartilhado por outros autores, como ASTOLFI \& PETERFALVI (1993), para os quais a educação em ciências deve dirigir seus esforços aos obstáculos e não, genericamente, às representações dos estudantes. Astolfi e Peterfalvi sustentam a idéia de "objetivo-obstáculo", porquanto permite formular metas essenciais para a educação científica, além de orientar as intervenções pedagógicas e a avaliação da aprendizagem. Os autores argumentam que os obstáculos apresentam uma característica transversal, perpassando várias representações dos estudantes, e sugerem que sejam considerados local e globalmente pelo ensino, de modo alternado. Além disso tanto as representações dos estudantes quanto os obstáculos que as sustentam, manifestam-se em uma rede de idéias que constitui um sistema, elementos que se apóiam e se reforçam mutuamente, o que os torna mais resistentes aos esforços de refutação. Desse modo, para Astolfi e Peterfalvi, os conflitos representam uma condição, entre outras, para a ultrapassagem dos obstáculos.

Outros autores consideram que a dimensão essencial da mudança envolveria as diferentes formas de raciocínio causal contidas nas formas evoluídas do pensamento científico e ausentes no domínio do pensamento espontâneo (ANDERSSON, 1986; ROZIER \& VIENNOT, 1991; GUTIERREZ \& OGBORN, 1992; PERKINS \& GROTZER, 2000). Os modelos propostos variam na extensão e sofisticação dos processos.

O trabalho pioneiro de ANDERSSON (1986) permitiu identificar, em diferentes conteúdos, a mesma estrutura causal, constituída por três elementos - agente, instrumento e objeto - interligados de modo linear e unidirecional. Segundo o autor, as regras básicas dessa "causalidade experencial" constituem o núcleo central das concepções espontâneas. De modo semelhante, ROZIER \& VIENNOT (1991) apresentam o "raciocínio linear causal" como estratégia de pensamento dos estudantes ao lidarem com sistemas de muitas variáveis. Nesse caso, as conexões temporais permitem uma redução do número de variáveis, que são consideradas, separadamente, na forma de uma narrativa. Isso traduz modos de pensar essencialmente distintos da característica sistêmica e interativa dos modelos científicos.

GUTIERREZ \& OGBORN (1992) procuram sofisticar a descrição dos modelos causais dos estudantes de modo a permitir não apenas a identificação de formas estáticas de raciocínio, mas também o acompanhamento e explicação da ocorrência de mudanças. Segundo os autores, as mudanças são decorrentes das interações dos sujeitos com um sistema físico, buscando satisfazer condições de consistência, correspondência com a experiência e robustez dos modelos propostos. Os autores apontam evidências que indicam compromissos dos estudantes com a causalidade, isto é, tentativas de elaborar explicações, mesmo quando estas pareçam circulares e formuladas a partir de elementos ad hoc. Apontam ainda para a existência de duas formas de causalidade, dinâmica e estrutura/ ${ }^{[2]}$ - as primeiras

2[2] HALBWACHS (1977) estabelece a mesma distinção, mas denomina-as, respectivamente, causalidade heterogênea e homogênea, conforme a causa da transformação esteja situada fora do sistema, quando se impõe a distinção entre causa e efeito, ou do interior do sistema, segundo sua natureza ou composição interna. 
agindo positivamente nos atributos dos materiais, enquanto as segundas produzem efeitos devido à estrutura ou às restrições do sistema. Em seu estudo, destacam a preferência dos estudantes, sobretudo aqueles mais jovens, pela causalidade dinâmica. Desse modo, os autores acompanham como os estudantes reconstroem seus modelos, partindo da estrutura uma causa, um efeito para sistemas em que muitas causas combinam na produção de um efeito dado.

PERKINS \& GROTZER (2000) sugerem que as dificuldades dos estudantes na aprendizagem em ciências decorrem de dois fatores essenciais: primeiro, os modelos de causalidade complexa do pensamento científico contrastam com a causalidade simples e linear com que os estudantes estão habituados a trabalhar; segundo, a aprendizagem em ciências envolve uma série de movimentos epistêmicos, no sentido de promover atitudes e estratégias de avaliação frente ao conhecimento. No que se refere à causalidade, os autores apresentam uma série de categorias, que procuram indicar as formas básicas prevalentes do pensamento causal espontâneo e de alguns domínios específicos da ciência, quanto aos seguintes aspectos: mecanismo causal, relações causais, previsão de resultados e explicação de novidades. Para cada um desses aspectos, propõem categorias de complexidade crescente, ressaltando a ausência de formas mais elaboradas no pensamento cotidiano e sua importância na organização das estruturas conceituais da ciência.

BORGES \& GILBERT (1999) investigam a progressão de modelos mentais utilizados por estudantes e profissionais com experiências diversas no que se refere aos circuitos elétricos e à natureza da eletricidade. Os modelos mentais são descritos como atribuição de estruturas e mecanismos ao real, a fim de prever e dar sentido à experiência. Desse modo, a aprendizagem em ciências é descrita como resultado de uma evolução gradual de modelos, ou seja, a evolução do sentido dado às coisas, daquilo que as constitui, do modo como funcionam e por que se comportam de uma certa maneira. Os autores sugerem que seus resultados sobre a progressão de modelos em eletricidade podem ser generalizados a outras áreas da ciência no que se refere a alguns aspectos, tais como mudança na abrangência e campo de validade dos modelos; diferenciação de conceitos básicos; transição de modelos qualitativos para quantitativos; mudança na ontologia; mudança na causalidade e formas de explicação adotadas.

Outro grupo de pesquisadores tem apontado, mais recentemente, para as dimensões culturais e sociais da ciência e dos processos de aprendizagem em ciências. Segundo os autores de um dos mais representativos trabalhos nessa área:

“... aprender ciências, portanto, envolve ser iniciado nas idéias e práticas da comunidade científica e tornar essas idéias e práticas significativas no nível individual. O papel do professor de ciências, mais do que organizar o processo pelo qual os indivíduos geram significados sobre o mundo natural, é o de atuar como mediador entre o conhecimento científico e os aprendizes, ajudando-os a conferir sentido pessoal às maneiras pelas quais as asserções do conhecimento 
são geradas e validadas." (DRIVER, ASOKO, LEACH, MORTIMER \& SCOTT, 1994: 6) $)^{3[3]}$.

Para esses autores, o conhecimento científico difere fundamentalmente do conhecimento de senso comum por suas entidades ontológicas, pelas metas e propósitos de cada uma dessas instâncias e pela necessidade de explicitar seus modos de raciocínio, em oposição ao caráter tácito do conhecimento cotidiano. Afirmam que os estudos sobre mudança conceitual no ensino de ciências não investigaram, de modo substantivo, as interações dos estudantes com as realidades simbólicas, ferramentas culturais da ciência. Em lugar de conceberem a eliminação do conhecimento cotidiano em detrimento do científico ou a subordinação do primeiro ao segundo, afirmam que a aprendizagem em ciências é mais bem caracterizada como construção de sistemas paralelos, relacionados a contextos específicos de interação social, com propósitos diferenciados. Embora reconhecendo que a aprendizagem em ciências envolve reestruturação de idéias, os autores consideram exagerada a ênfase na natureza teórica das concepções dos estudantes. Assim, mais do que mudar de um conjunto de teorias para outro, a aprendizagem em ciências envolve a compreensão do que constitui uma teoria científica.

A análise das relações entre conhecimento científico e conhecimento de senso comum é matriz de vários trabalhos que procuram elucidar o que significa aprender ciências. DÉSAUTELS \& LAROCHELLE (1990) defendem a tese de que a apropriação de conhecimentos científicos é dependente do quadro epistêmico implícito que guia a atividade cognitiva dos estudantes. Assim, por exemplo, as crianças acreditam que as sensações dão acesso imediato à compreensão, elaboram com freqüência raciocínios circulares, baseados nas propriedades dos objetos, e recorrem à idéia de substância para explicar uma diversidade de fenômenos. Essas convicções ontológicas e epistemológicas fundamentais constituem a base da física ingênua e, para elas, deve ser dirigida a atenção das atividades de ensino. Os autores apóiam-se nas noções bachelardianas de "perfil epistemológico" e de "psicanálise dos conhecimentos prévios" como condição básica do desenvolvimento da ciência. Elaboram estratégias de ensino que denominam "perturbação epistemológica", o que significa o questionamento do estatuto epistemológico dos conhecimentos prévios e o reconhecimento da importância de se considerarem os postulados e regras do "jogo" de construção do conhecimento científico. O processo é conduzido pela proposição de problemas abertos, que devem ser investigados pelos estudantes, organizados em grupos, visando elaborar modelos e submetê-los à apreciação dos colegas. A mudança é então descrita como resultado de uma complexificação das estruturas conceituais dos sujeitos, que não pode ser reduzida à eliminação ou substituição de suas concepções prévias. Os conhecimentos científico e espontâneo não são intercambiáveis, pelo fato de não responderem às mesmas questões nem, tampouco, perseguirem os mesmos propósitos.

A partir dessa mesma noção bachelardiana de perfil epistemológico, MORTIMER (1995) sugere que a aprendizagem em ciências deve promover a evolução de perfis conceituais dos

\footnotetext{
${ }^{3[3]}$ Esse mesmo artigo foi traduzido e publicado recentemente na "Química Nova na Escola”, n. 9, maio 1999, p. 3140 .
} 
estudantes. Assim como o perfil epistemológico, o perfil conceitual estabelece uma hierarquia entre as diferentes zonas na construção de conceitos, caracterizada por conter categorias de análise com poder superior às anteriores. Abrange, no entanto, outros aspectos próprios da evolução das idéias dos estudantes em situações de ensino. Assim, as zonas que compõem o perfil conceitual diferem entre si não apenas por sua filiação epistemológica, mas também por suas características ontológicas. O autor sugere dois momentos no processo de aprendizagem. O primeiro deles corresponde à aquisição de um conceito em um nível específico do perfil, tendo em vista a natureza dos obstáculos ontológicos e epistemológicos que se contrapõem a seu desenvolvimento. Nesse momento, o papel do professor é fundamental no sentido de explicitar a agenda, identificar os obstáculos, tentar minimizá-los e auxiliar os estudantes a superá-los. O segundo momento consiste na tomada de consciência, por parte dos estudantes, de seus próprios perfis, bem como da avaliação das limitações e poder explicativo dos elementos que o compõem. Segundo o autor, uma das conseqüências da noção de evolução dos perfis conceituais consiste em permitir ensinar um conceito em um certo nível de complexidade sem que seja necessário fazer referência aos níveis anteriores, a menos que as concepções prévias constituam obstáculos ao desenvolvimento do novo conceito. Nesse caso, será necessário lidar com a contradição, o que pode ocorrer em qualquer momento do processo de ensino, e não apenas no início deste.

O conceito de perfil conceitual é re-examinado pelo autor (MORTIMER, 1998; 2001) a partir de estudos em sociolingüística. Segundo essa interpretação, os conceitos emergem da comunicação humana, sendo inevitavelmente povoados por múltiplas vozes ou perspectivas. A análise das interações discursivas em sala de aula revela como diferentes linguagens sociais (científica e cotidiana), usadas alternadamente por professores e alunos, são colocadas em contato e geram novas formas de entendimento.

Baseando-se em estudos de sociologia do conhecimento, SOLOMON (1983, 1992) identifica duas esferas de conhecimento - científica e cotidiana - distintas em sua gênese e modos de operação. Apesar da independência relativa desses dois sistemas, a autora apresenta dados empíricos relativos ao conceito de energia que corroboram a hipótese de que a aprendizagem duradoura e efetiva é aquela capaz de distinguir e operar nos dois domínios de conhecimento:

"Os níveis mais profundos de compreensão não são atingidos nas formas abstratas da física 'pura', ou através de uma batalha para eliminar as estruturas inexatas da comunicação social, mas sim pela fluência e discriminação com que aprendemos a nos mover entre esses dois domínios contrastantes de conhecimento." (1983: 58)

De modo semelhante, trabalhando na perspectiva da cognição situada, CARAVITA \& HALLDÉN (1994) alegam que:

"a mudança não se localiza em estruturas de conteúdo ou necessariamente se dá através de conflitos e pela substituição de idéias e práticas preexistentes. $A$ mudança envolve um conjunto de maneiras de pensar sobre um domínio conceitual que são evocadas em contextos de ação e de discurso específicos. 
Ela é o resultado de uma diferenciação 'oportunística' entre contextos de interpretação. (1994: 89).

As autoras lamentam que os conceitos gerais de equilibração das estruturas cognitivas de Piaget tenham servido de suporte a uma noção de progresso como ponto final normativo, cuja direção é devida a processos endógenos e não a processos de mediação e ação cultural. Questionam, ainda, o uso da metáfora da rede semântica para caracterizar as formas de conhecimento dos estudantes, uma vez que, através deles, se destacam os aspectos estáticos em detrimento do dinamismo essencial das representações mentais. Em lugar disso, Caravita e Halldén afirmam que os aspectos fundamentais da aprendizagem residem no entendimento das diferentes formas de explicação envolvidas na ciência e no pensamento cotidiano, no nível de seus propósitos, sua ontologia e sua causalidade. Assim, os estudantes devem ser levados a refletir sobre as questões a serem respondidas, o que vale como respostas a essas questões e quais são as exigências para a argumentação em ciência. O objetivo da educação em ciências deve ser o de estender o repertório de idéias sobre o mundo físico e social objetivando incrementar sua organização e coerência. As autoras consideram, ainda, que importantes diferenças entre a história da ciência e o contexto de aprendizes em ambiente escolar foram menosprezados, resultando numa dissociação das mudanças dos processos mais gerais de aprendizagem escolar.

A perspectiva racionalista dos modelos de aprendizagem por mudança conceitual é também criticada por PINTRICH, MARX \& BOYLE (1993). Os autores examinam fatores contextuais de sala de aula que atuam como moderadores das crenças motivacionais dos estudantes e conduzem ao desenvolvimento de processos cognitivos específicos. Desse modo, seria possível investigar e intervir nas variáveis que predispõem os estudantes a reconhecer um problema e a decidir pela sua resolução por meio de recursos cognitivos mais sofisticados. Pintrich e colaboradores destacam vários desses fatores contextuais (estrutura da tarefa, autoridade e distribuição dos papéis, modos de conduzir e negociar a avaliação, aspectos gerenciais da sala de aula, suporte para realização das tarefas) em relação com fatores motivacionais (metas de promoção, motivações epistêmicas, interesse pessoal, valor utilitário, autoconfiança) e a processos cognitivos (atenção seletiva; ativação de conhecimentos prévios, processamento de informação, atitudes metacognitivas, auto-regulação, elaboração e resolução de problemas).

\subsection{As mudanças para além de aspectos conceituais}

Esse breve retrospecto da pesquisa quanto à compreensão do sentido dos processos de mudança que acompanham as aprendizagens em ciências indica que, muito além dos aspectos conceituais, as mudanças envolvem propósitos, atitudes, metodologia, ontologia, epistemologia e um processo continuado de reflexão sobre o próprio conhecimento. Poderíamos dizer que todos esses fatores estariam envolvidos, mas o que importa mesmo é que, ao final do processo, os estudantes tenham acesso aos verdadeiros produtos da atividade científica. Entretanto, consideramos que não seja este o objetivo central da educação científica voltada para uma compreensão básica por todos, no interior de sociedades crescentemente influenciadas por questões científicas e tecnológicas. 
O que se pretende, por meio da educação em ciências, é promover novas formas de ver o mundo, refletir sobre fenômenos e analisá-los, ir além das aparências, combinar evidências e inferências em atividades de modelagem de aspectos da realidade que se procura melhor compreender para intervir e agir. Enfim, a meta fundamental da educação científica consiste em fazer com que os jovens entendam o que é a ciência, quais as "regras" desse jogo, para que possam se beneficiar, pessoal e socialmente, da racionalidade científica.

Assim, os propósitos centrais de um ensino comprometido com o desenvolvimento dos estudantes não devem estar dirigidos apenas a mudanças nos repertórios conceituais em domínios específicos do conhecimento, mas a mudanças mais profundas, relativas aos modos de pensar e organizar as experiências, de refletir e argumentar acerca do próprio conhecimento e da ciência enquanto empreendimento social mais amplo. Denominamos "mudanças cognitivas" ${ }^{\prime 4[}$ a esse amplo leque de transformações, com fortes componentes afetivos e motivacionais, que entendemos serem graduais e permeados por uma dialética de continuidades e rupturas.

Certamente o modo de promover tais mudanças consiste em propor e examinar problemas locais, partindo de cenários concretos para representações e destas para estruturas mais profundas. Esses conhecimentos são, em tese, transferíveis e generalizáveis a outros contextos, mas sabe-se que isso não ocorre diretamente e sem resistências. A cada novo contexto, retorna-se ao plano da experiência e, freqüentemente, o fazemos a partir de estratégias cognitivas mais primitivas, porquanto mais robustas e econômicas. Entretanto as possibilidades de transferência de formas avançadas de conhecimento são tanto maiores quanto mais significativas e reiteradas forem as experiências locais em que sejam utilizadas com sucesso. Os processos de mudança que se almeja são, portanto, processos de longo prazo, a ocupar todo o período de escolarização obrigatória, em níveis crescentes de abstração.

\section{A Progressão das Formas de Entendimento dos Estudantes}

Convém, então, atentar para o problema da graduação das demandas cognitivas na organização do currículo e na construção de seqüências ou unidades de ensino. O problema, longe de estar bem formulado e equacionado, apresenta-se, ainda, de forma incipiente pela pesquisa, cujos resultados apresentamos de modo sucinto.

LEMEIGMAN \& WEIL-BARRAIS (1994) examinam o problema das mudanças cognitivas em mecânica, procurando descrever, com mais detalhes, as atividades cognitivas envolvidas, assim como a natureza das mudanças que ocorrem no processo. Avaliam que a mudança nas representações dos estudantes acerca dos fenômenos físicos envolve quatro aspectos centrais: 1. representações implícitas, pessoais e inconscientes tornam-se conscientes, explícitas e compartilhadas pela comunidade de aprendizes; 2. representações locais tornam-se

\footnotetext{
${ }^{4[4]}$ A expressão "mudança cognitiva” é proposta por NEWMAN, GRIFFIN \& COLE (1989:.59) para caracterizar os processos que envolvem interações dialéticas entre o mundo social e as mudanças individuais. Em nossa perspectiva é considerada como reorganização de sistemas de significação, conjunto de processos de múltipla natureza (ontológica, epistemológica e axiológica) que ocorrem quando um sujeito modifica seus pontos de vista em relação a um dado objeto do conhecimento.
} 
representações gerais, com controle por meio de critérios, tais como invariância, coerência, parcimônia e funcionalidade; 3. rigidez de uma representação converte-se em flexibilidade por descentração, diferenciação e integração; 4. representações centradas nos objetos e em eventos transformam-se em representações sistêmicas.

Contudo, dada a lentidão das mudanças cognitivas, os autores consideram necessário estabelecer um ponto de vista desenvolvimentista acerca da formação de conceitos na criança. Assumindo o caráter progressista das construções dos estudantes, Lemeigman e Weil-Barrais consideram crucial para o ensino auxiliá-los naqueles níveis em que já adquiriram certo grau de autonomia de tal modo que podem adquirir ou elaborar novos conhecimentos. Para isso, sugerem a eleição de representações precursoras, a partir de análises epistemológicas e psicológicas:

"Como nem sempre é possível que os alunos tenham acesso direto aos modelos físicos científicos com base em representações que eles podem elaborar 'espontaneamente', entendemos que seria benéfico planejar modelos intermediários com o propósito do ensino. Esses modelos servem como precursores que, embora difiram dos modelos dos cientistas, ainda preservam algumas das características destes. [...] Esses modelos podem tornar-se precursores de modelos sistêmicos se os estudantes forem capazes de apoderar-se das similaridades e diferenças entre as representações precursora e científica." (LEMEIGMAN \& WEIL-BARRAIS, 1994: 103)

A delimitação de "níveis de formulação" dos conteúdos do ensino constitui, para DE VECCHI (1994), em um dos problemas cruciais colocados à didática em ciências. O autor sugere que os níveis de formulação devem corresponder aos processos de formação de conceitos e ter por referência obstáculos susceptíveis de serem superados em função do nível de desenvolvimento da criança. Quando se passa de um nível de formulação a outro, faz-se necessária uma ruptura importante, com reorganização e remodelagem das concepções precedentes. A reorganização implica que a leitura de mundo não pode mais ser a mesma, uma vez que se faz necessário reconstruir um modelo explicativo mais pertinente.

Uma outra possibilidade para a definição de formas de abordagem de um conteúdo consiste em fazê-lo segundo as práticas sociais de referência. Para De Vecchi, tal questão, a que denomina "registros de formulação", é complementar à anterior. Assim sendo, a definição do currículo incluiria opções quanto aos registros e aos níveis de formulação mais adequados ao tratamento de determinados conceitos. Entretanto, os níveis de formulação também definem campos de validade precisos, além dos quais aquela formulação do conceito revela-se inadequada e insuficiente. Desse modo, a definição de níveis de formulação precisos e operacionais se dá pela dialética entre a análise do conceito em relação aos campos sociais de referência e às concepções dos estudantes. O autor apresenta alguns exercícios de níveis de formulação dos conceitos de "semente", "alimentação" e "respiração" ao longo do currículo. 
Tomando por referência o mesmo problema de graduação dos níveis de abordagem dos conteúdos do ensino, DYKSTRA, BOYLE \& MONARCH (1992) afirmam que não basta apresentar uma seqüência de modelos crescentemente sofisticados acerca de um domínio conceitual ou ainda, de modo mais explícito, fornecer uma organização hierárquica dos conteúdos escolares. Em lugar disso, os autores desenvolvem uma seqüência de ensino em mecânica, em que representam estados sucessivos de conhecimento dos estudantes e as mudanças envolvidas, conforme diagrama reproduzido na FIG. 1.

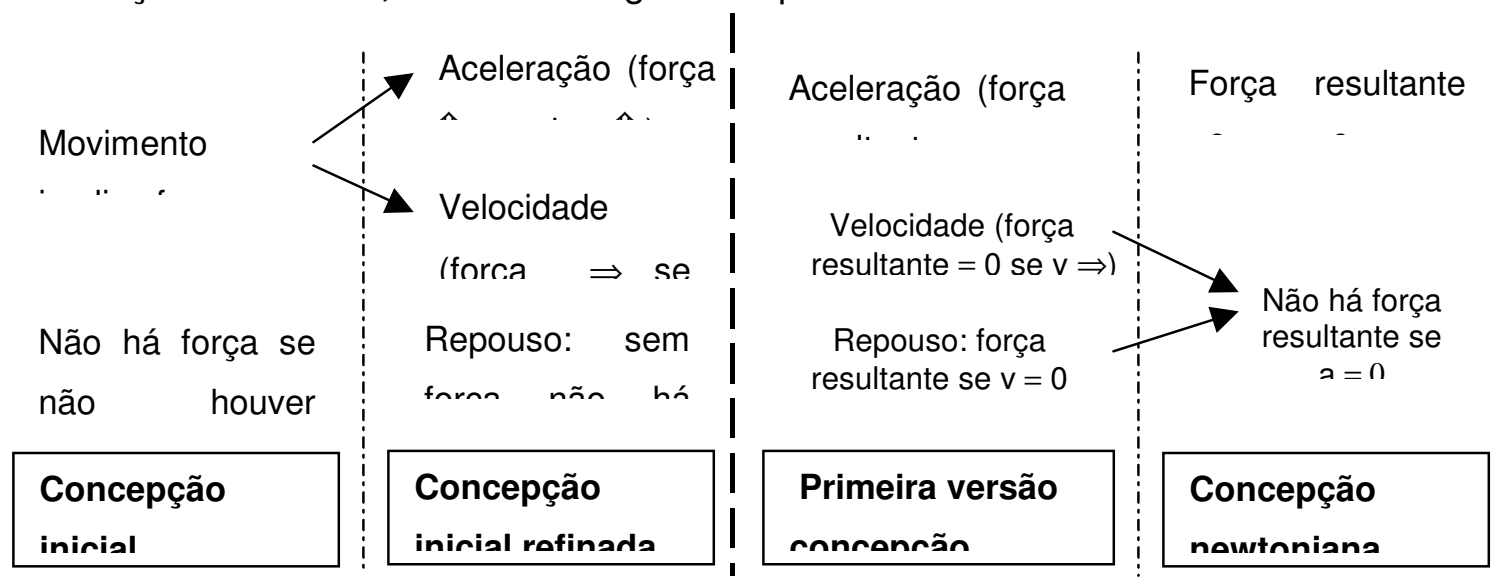

Figura 1: Mapa de concepções, em que se indica uma seqüência de mudanças ao longo de um curso. As linhas pontilhadas representam as mudanças, $\Uparrow$ representa incremento $\mathrm{e} \Rightarrow$ representa valores constantes (DYKSTRA, BOYLE \& MONARCH, 1992: 624).

Os autores denominam esse tipo de representação de "mapas de concepções", cujo propósito reside em organizar e tornar explícitos os conteúdos essenciais do conhecimento dos estudantes, de modo a selecionar situações de ensino destinadas a provocar desequilíbrios sucessivos. Concluem que "mapas de concepções nos capacitam a monitorar o processo de aprendizagem de maneira mais precisa e para fornecer conteúdo para o ensino planejado de modo a tornar efetiva aquela aprendizagem" (DYKSTRA et al., 1992: 633).

Ao tratar do problema de graduação dos níveis de compreensão ao longo do currículo, TIBERGHIEN (1998) destaca a necessidade de se diferenciarem os ritmos do ensino dos ritmos e processos de aprendizagem. Assim, o fato de certas seqüências didáticas estabelecerem fases sucessivas de abordagem não significa que os estudantes em sua atividade concreta venham a obter os patamares desejados nos tempos previstos. Para amenizar tais conflitos, a autora sugere que os conteúdos fundamentais devem ser tratados de modo recursivo e relacional, a fim de permitir múltiplas oportunidades de entendimento.

Ao se reportar a pesquisas relacionadas a seqüências didáticas envolvendo conteúdos da física térmica para crianças de 12-13 anos de idade, Tiberghien aponta certos progressos nas formas de compreensão dos estudantes, embora não tenham sido alcançados os objetivos normalmente estabelecidos pelo currículo. A autora considera necessário restabelecer 0 equilíbrio entre as metas do ensino e as aquisições dos estudantes, propondo, explicitamente, a introdução de noções intermediárias, tanto nos materiais de ensino quanto nos guias curriculares e na formação de professores. Assim, conclui afirmando que: 
"Acreditamos que a necessidade da introdução dessas noções intermediárias se deva à sua capacidade de serem aprendidas, à sua eficiência na interpretação de uma parte do mundo material e ao fato de estarem mais próximas do conhecimento de física que o conhecimento inicial dos alunos, mesmo que elas ainda não sejam completamente corretas" (TIBERGHIEN, 1998: 43).

O estudo de BROWN \& CLEMENT (1992), realizado a partir do refinamento e ajuste gradual de uma unidade de força e movimento frente aos resultados de aprendizagem, aponta para a importância, no planejamento e desenvolvimento de unidades de ensino, da utilização de conceitos intermediários (stepping stones) em direção aos conceitos físicos mais abstratos. Os autores dão, como exemplo de noções intermediárias, termos ou expressões como "reter" (holdback) e "seguir em movimento" (keep going), que passam a ser largamente utilizados pelos estudantes assim que mencionados pelo professor. Tais noções podem ser, posteriormente, integradas em um único conceito de "inércia" como resistência à aceleração, tanto positiva quanto negativa.

Outros estudos apontam para a identificação de categorias gerais que permitam descrever a progressão dos níveis de complexidade das formulações dos estudantes em situações de aprendizagem escolar. O grupo de pesquisas em ensino de física da Universidade de Bremen (WELZEL, 1998; WELZEL \& AUFSCHNAITER, 1997) examina esse problema acompanhando as pautas de interações dos estudantes, quando se engajam em discussões, com seus pares e professores, acerca de fenômenos físicos. Os autores afirmam ser impossível avaliar a aprendizagem com base em processos individuais e buscam, em lugar disso, evidências no processo de construção de significados em contextos de interação social frente a uma situação problema a ser examinada e manipulada pelos estudantes. Uma vez gravadas e transcritas, as falas dos estudantes são interpretadas e refraseadas em "idéias", a partir de suas ações e propósitos. Essas "idéias" são submetidas, então, à análise dos níveis de complexidade.

Welzel e colaboradores sugerem o uso de dez níveis de análise, em graus crescentes de complexidade, a saber: 1 . objetos, com a distinção estável de figura/fundo; 2 . aspectos, que consistem em correspondências entre objetos e/ou identificação de características específicas; 3. operações, ou seja, variações sistemáticas dos objetos de acordo com seus aspectos; 4. propriedades, construção de classes de objetos com base em aspectos comuns ou distintos; 5 . eventos, que estabelecem correspondências entre propriedades estáveis de classes de objetos; 6. programas, com variação sistemática de uma propriedade de acordo com outras propriedades estáveis; 7. princípios, através da construção de covariações estáveis de pares de propriedades; 8. concepções, correspondências entre vários princípios com as mesmas ou com diferentes propriedades variáveis; 9. redes, com variação sistemática de um princípio de acordo com outros; 10. sistemas, construção de redes estáveis de variados princípios.

Os autores desenvolvem estudos diversos e sustentam que os alunos, engajados na ação e na discussão com seus pares, apresentam uma clara evolução, ao longo da tarefa, de níveis de abordagem mais baixos para níveis mais complexos. Por outro lado, afirmam que essa progressão não é linear e caracteriza-se por uma série de recuos, que indicam, porém, uma evolução gradual e uma estabilização a partir de determinado momento da tarefa. Além 
disso, esse desenvolvimento mostra-se fortemente vinculado a contextos específicos e dependente das interações atuais. Concluem os autores que o ensino deve engajar os estudantes dos níveis mais baixos aos níveis mais abstratos, procurando guiá-los na atividade de "cientificizar" o mundo e não, necessariamente, em orientá-los na obtenção de determinados conceitos, como produtos da ciência. Devemos ressaltar que os dados apresentados pelos autores não parecem suficientes para caracterizar todos os dez níveis propostos. Além disso, as categorias têm pouco a ver com explicações dos processos, e concentram-se, quase sempre, nas descrições dos mesmos. De todo modo, a progressão de uma atenção dirigida aos objetos, passando por eventos e atingindo sistemas, parece indicar um caminho de construção, cuja generalidade precisa ser justificada e examinada empiricamente.

MORTIMER (1999) propõe uma análise microgenética de explicações elaboradas por estudantes em situações de aprendizagem em ciências, em que decompõe o processo em uma seqüência de etapas, com a finalidade de destacar o que ocorre entre uma etapa e outra. As categorias de análise utilizadas foram elaboradas a partir de estudos filosóficos acerca do problema da causalidade na ciência. O autor sugere uma distinção inicial entre descrição, explicação e generalização na construção de interpretações de fenômenos por parte dos estudantes. A diferença entre descrições e explicações reside no fato de que as segundas atribuem relações entre entidades utilizadas para caracterizar os sistemas e se valem de mecanismos, ou modelos, para lidar com os fenômenos. Por sua vez, a generalização resulta de um esforço de descontextualização, tendo-se em vista que as explicações passam a ser vistas como atributos das entidades envolvidas e não apenas como propriedade de um fenômeno particular:

\section{"A generalização completa o movimento de descontextualização / recontextualização em direção a uma relação puramente simbólica, intralingüística, entre os signos, não mais como referentes de objetos $e$ fenômenos extralingüísticos, mas enquanto categorias gerais da matéria e dos fenômenos criados nas relações intralingüísticas" (MORTIMER, 1999: 8).}

$\mathrm{Na}$ análise do fluxo do discurso em sala de aula, Mortimer destaca um movimento progressivo de descontextualização ou recontextualização, que se desloca de descrições para explicações e generalizações. Destaca, além disso, que os estudantes apresentam uma tendência de utilizar generalizações previamente aprendidas como base para descrições de fenômenos a serem explicados, o que revela uma dinâmica entre essas categorias na construção de argumentos em situações de aprendizagem escolar.

POZO \& GÓMEZ CRESPO (1998) apresentam uma análise dos processos de mudança cognitiva assentados sobre três dimensões - ontológicas, epistemológicas e conceituais. Para cada uma delas os autores descrevem formas de progressão sucessivas e majorantes, de modo a modificar substancialmente os princípios em que estão baseados, implicitamente, os modos de processamento e organização do conhecimento. Reproduzimos, a seguir, o quadro sintético das mudanças no sentido proposto pelos autores: 


\section{PRINCÍPIOS EPISTEMOLÓGICOS}

\begin{tabular}{|c|c|c|c|c|}
\hline REALISMO INGÊNUO & & $\begin{array}{c}\text { REALISMO } \\
\text { INTERPRETATIVO }\end{array}$ & & CONTRUTIVISMO \\
\hline $\begin{array}{l}\text { A realidade é tal como } \\
\text { se vê. O que não se } \\
\text { percebe não é } \\
\text { concebível. }\end{array}$ & 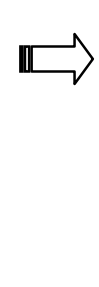 & $\begin{array}{l}\text { A realidade existe e } \\
\text { tem suas } \\
\text { propriedades, embora } \\
\text { nem sempre se possa } \\
\text { conhecê-la }\end{array}$ & 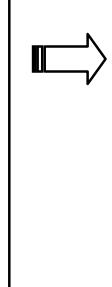 & $\begin{array}{lr}\text { O } & \text { conhecimento } \\
\text { científico é } & \text { uma } \\
\text { construção } & \text { que } \\
\text { proporciona } & \text { modelos } \\
\text { alternativos } & \text { para }\end{array}$ \\
\hline
\end{tabular}

\begin{tabular}{|c|c|c|c|c|}
\hline ESTADOS & \multirow{2}{*}{ 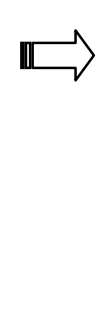 } & PROCESSOS & \multirow{2}{*}{$\|$} & SISTEMAS \\
\hline $\begin{array}{l}\text { Interpretação do } \\
\text { mundo em termos de } \\
\text { estados, de maneira } \\
\text { desconectada entre }\end{array}$ & & $\begin{array}{l}\text { Os fenômenos são } \\
\text { interpretados como } \\
\text { uma sucessão de } \\
\text { fatos, relacionados }\end{array}$ & & $\begin{array}{l}\text { Os fenômenos se } \\
\text { interpretam-se a partir } \\
\text { de um conjunto de } \\
\text { relações complexas }\end{array}$ \\
\hline \multicolumn{5}{|c|}{ PRINCÍPIOS CONCEITUAIS } \\
\hline \multicolumn{5}{|c|}{ PRINCÍPIOS ONTOLÓGICOS } \\
\hline
\end{tabular}

\begin{tabular}{|l|}
\hline \multicolumn{2}{|c|}{ FATOS OU DADOS } \\
\hline Os fenômenos e os \\
fatos são descritos em \\
função \\
\hline
\end{tabular}

\begin{tabular}{|c|}
\hline CAUSALIDADE \\
\hline $\begin{array}{lr}\text { Os } & \text { fenômenos } \\
\text { explicam-se } & \text { mediante } \\
\text { relações } & \text { causais }\end{array}$ \\
\hline
\end{tabular}

$\|$\begin{tabular}{ll|}
\multicolumn{3}{|c|}{ INTERAÇÃO } \\
\cline { 2 - 2 } $\begin{array}{l}\text { As propriedades dos } \\
\text { corpos e dos } \\
\text { fenômenos }\end{array}$ \\
\hline
\end{tabular}

\begin{tabular}{|l|}
\hline \multicolumn{2}{|c|}{ MUDANÇAS SEM } \\
CONSERVACÃO \\
\hline Muda apenas aquilo \\
que se vê alterar-se. \\
Necessidade de \\
explicar o que muda, \\
\hline
\end{tabular}
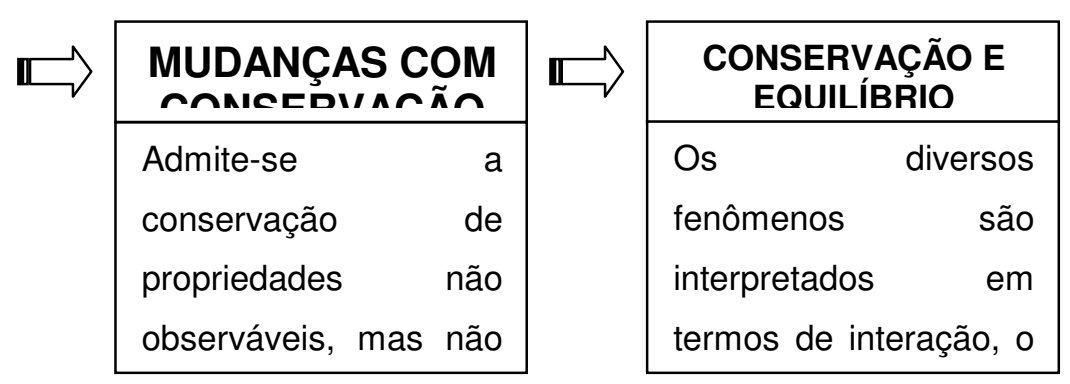

\begin{tabular}{|c|}
\hline \multicolumn{2}{|c|}{$\begin{array}{c}\text { RELAÇÕES } \\
\text { QUALITATIVAS }\end{array}$} \\
\hline $\begin{array}{l}\text { Os fenômenos são } \\
\text { interpretados de modo }\end{array}$ \\
\hline
\end{tabular}
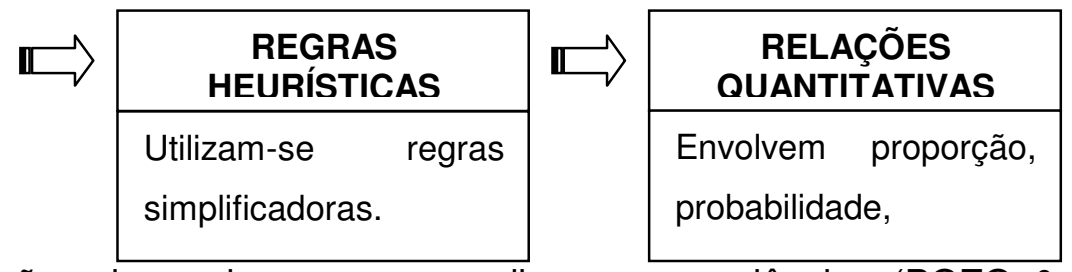

Quadro 1: Três dimensões de mudança na aprendizagem em ciências (POZO \& GÓMEZ CRESPO, 1998: 120). 
A evolução dos entendimentos dos estudantes acerca da natureza do conhecimento científico, ou seja, a dimensão epistemológica da mudança, é descrita por LEACH, DRIVER, MILLAR \& SCOTT (1997) segundo três modelos fundamentais. O primeiro deles consiste no raciocínio baseado em fenômenos, isto é, sem diferenciação entre evidências e inferências ou, ainda, descrições e explicações. Seu objetivo é o de produzir fenômenos novos e não o de compreendê-los ou explicá-los. O segundo caracteriza-se por um raciocínio que se apóia em relações ou correlações, de natureza indutiva, as quais se expressam predominantemente por causalidade linear. O terceiro compreende o raciocínio baseado em modelos, capaz de avaliar teorias com base em evidências e de reconhecer o caráter problemático e aberto da investigação científica. Os autores lamentam haver poucos estudos sobre os aspectos epistemológicos do conhecimento prévio dos estudantes e sua evolução ao longo da escolaridade. Embora entendam não haver hierarquia entre as três formas de raciocínio apresentadas (com o que discordamos), afirmam que poucos estudantes desenvolvem 0 terceiro modelo; havendo uma transição, com a idade, do primeiro para o segundo modelo, sendo este largamente predominante.

Em pesquisas recentes (AGUIAR \& FILOCRE, 1999; AGUIAR JR. 2001), procuramos destacar como elementos de análise de conteúdos de ensino e da aprendizagem em ciências as sucessões intra, inter e trans-objetais propostas por PIAGET \& GARCIA (1984). O primeiro nível, intra-objetal, consiste em análises centradas nas qualidades dos objetos, seus atributos e propriedades. É predominantemente descritivo e pouco analítico. Freqüentemente fecha-se na certeza de que as coisas devem ser, necessariamente, como se apresentam e que o mundo das sensações e aparências tem correspondência com a realidade a ser conhecida. No segundo nível de elaboração, denominado inter-objetal, o sujeito volta-se à coordenação entre os observáveis, donde resulta um deslocamento das descrições de estados à análise das transformações. Desse modo, o sujeito passa a deslocar o olhar de objetos a eventos, indicando regularidades nas relações entre os conceitos. Finalmente, no terceiro nível, transobjetal, o sujeito procura sistemas de composição mais abrangentes, reunidos em estruturas de conjunto que lhes permitam explicar ocorrências e prever novos acontecimentos.

De qualquer modo, segundo essa perspectiva, em qualquer etapa de conhecimento que se considere, estamos sempre diante de três perguntas fundamentais: 1. o que é isso, 2. como funciona e 3. como se explica. Assim, cada um dos níveis de conhecimento - intra, inter e transobjetais - comporta, ele mesmo, a tríade, num deslocamento progressivo para sistemas de explicação mais abrangentes e abstratos. Esse modelo teórico foi utilizado, com sucesso, na análise de um curso de eletricidade básica (AGUIAR JR, 1999) e no planejamento e avaliação de um curso introdutório à física térmica (AGUIAR JR., 2001; AGUIAR JR. \& FILOCRE, 2001).

O exame desses vários estudos permitem dizer que o problema da ordenação das dificuldades de aprendizagem em ciências tem sido recentemente enfocado pela pesquisa a partir de várias perspectivas, mesmo que ainda de forma incipiente e sem que as implicações dos modelos propostos tenham sido suficientemente examinadas no campo da prática educativa. Todos esses trabalhos assentam-se sobre o pressuposto de que a mudança cognitiva é um processo de longo prazo e que pode ser analisada e favorecida por intervenções e atividades de ensino que apontem para uma progressiva complexificação dos conteúdos do ensino. 
Uma das direções dessa pesquisa consiste em examninar a maior efetividade do ensino suportado pela elaboração de níveis intermediários de entendimento dos conceitos e pela complexificação crescente de modelos físicos examinados. Outra linha de investigação, complementar à anterior, procura identificar e fundamentar as direções da evolução das formas de entendimento dos estudantes. Para isso, têm sido utilizados diferentes referenciais teóricos, decorrentes de análises epistemológica dos conteúdos e da análise de pautas de interação discursiva em sala de aula. Em que pese a diversidade desses referenciais, os resultados convergem em relação a alguns aspectos. Por exemplo, vários estudos apontam para a importância de qualificar a descrição dos sistemas físicos envolvidos e a compreensão dos fatores em jogo para sustentar modelos explicativos mais globais e abstratos. Além disso, a passagem de um olhar dirigido a "objetos", passando por "eventos" e atingindo o estatuto de "sistemas" de composição e compensação é evocada por vários pesquisadores a partir de abordagens diversas, o que fortalece o sentido dessa proposição.

\section{Contribuições e novos direções para a pesquisa e a prática educativa}

O exame da produção recente da pesquisa em educação em ciências nos permite destacar como é restritivo o adjetivo "conceitual" para caracterizar os complexos mecanismos de mudança envolvidos na aprendizagem em ciências. Muito além de aspectos estritamente "conceituais" a pesquisa tem revelado a complexidade dos fatores envolvidos e a importância de dimensões epistemológica, ontológica, metodológica, axiológica e motivacional nos processos de mudança na ciência e na aprendizagem em ciências. Além disso, a expressão "mudança conceitual" tem sido identificada com as primeiras abordagens do problema, em particular ao modelo proposto por Posner et al (1982). Segundo esse modelo, a aprendizagem por mudança conceitual é entendida como escolha racional entre teorias, de caráter científico ou cotidiano, que deveria culminar no abandono de concepções de senso comum. Muito além desses primeiros ensaios do problema, a produção da pesquisa em educação em ciências tem permitido estabelecer um consenso relativo quanto a alguns dos seus aspectos fundamentais. Entre eles, destacamos:

I O processo de mudança é complexo, não linear e prolongado no tempo. O caráter gradual e evolucionário dos processos de mudança que acompanham as aprendizagens em ciências tem sido enfatizado em detrimento da imagem de mudanças radicais, envolvendo simultaneamente múltiplos fatores.

I A mudança ocorre com a co-existência de modelos explicativos de origens diversas. Não se trata de uma mera substituição de um conjunto de idéias ou mecanismos explicativos por outros, de maior abrangência e generalidade.

Os fatores contextuais da sala de aula e as práticas sociais específicas dos estudantes em processos de aprendizagem escolar devem ser levados em consideração nos estudos e nas estratégias de ensino a serem implementadas.

Aspectos sociais e individuais estão imbricados no aprender ciências e devem ser levados em consideração na formulação e desenvolvimento de estratégias de ensino. $O$ ambiente de aprendizagem deve ser rico e diversificado, envolvendo tarefas de debate e 
argumentação de idéias entre pares, mediadas pela ação docente, assim como atividades que promovam a reflexão dos estudantes sobre o próprio conhecimento.

A mudança cognitiva envolve, necessariamente, mudanças na compreensão dos estudantes acerca da natureza da ciência e da atividade científica. Significa, sobretudo, introduzir os estudantes em novas formas de gerar e validar conhecimentos.

I As concepções dos estudantes não constituem um todo indiferenciado de idéias. Maior atenção deve ser dada a um pequeno conjunto de crenças dos estudantes, de natureza epistemológica e ontológica, que parecem dirigir as produções dos estudantes em contextos específicos e o modo como interpretam as informações culturalmente disponíveis.

As pesquisas permitem apontar direções efetivas para a pesquisa e o ensino de modo a promover e sustentar mudanças cognitivas na aprendizagem em ciências. As direções apontadas são diversas, mas não necessariamente excludentes. Assim, alguns dos fatores essenciais na promoção de mudanças seriam:

I A introdução dos estudantes nas "regras do jogo" da produção, validação e avaliação de conhecimentos pela ciência (DUSCHL \& GITOMER, 1991; DRIVER ET AL., 1994).

I O aprendizado de técnicas de abstração e modelamento do real, em detrimento de considerações lógicas acerca da consistência das teorias (NERSESSIAN, 1992).

I O desenvolvimento de modelos causais de complexidade crescente (LEMEIGMAN \& WEILBARAIS, 1994; AGUIAR \& FILOCRE, 1999; BORGES \& GILBERT, 1999; PERKINS \& GROTZER, 2000) e a exploração de modelos intermediários (DYKSTRA et al, 1992; BROWN \& CLEMENT, 1992; TIBERGHIEN, 1998).

) O desenvolvimento de atitudes metacognitivas dos estudantes, de modo que possam elaborar estruturas teóricas de maior sistematicidade, coerência e poder explicativo (VOSNIADOU \& IOANNIDES, 1998; HEWSON \& THORLEY, 1989).

I O reconhecimento e exploração de diferentes domínios de conhecimento, científico e cotidiano (SOLOMON, 1983; CARAVITA \& HALLDÉN, 1994; MORTIMER, 1995; DESALTELS E LAROCHELLE).

Pode-se, ainda, destacar a existência de tensões e perspectivas teóricas divergentes entre os vários autores que tratam da problemática das mudanças cognitivas. Existe, por exemplo, uma tensão entre abordagens construtivistas e sócio-interacionistas, expressando um olhar mais centrado no sujeito da aprendizagem ou nas mediações culturais. Embora compreendidos enquanto aspectos complementares, a questão a saber é o que dirige e sustenta os processos de mudança, se os fatores endógenos da equilibração ou a pressão social e as ferramentas culturais disponíveis. Outro ponto de divergência consiste em examinar a natureza supostamente teórica e estruturada dos conhecimentos prévios dos estudantes ou em compreendê-los em permanente movimento, fortemente vinculados a contextos específicos de interação. Diferentes abordagens têm sido, ainda, evocadas a partir dos temas da estabilidade e da mudança, com autores que enfatizam um ou outro desses aspectos.

A revisão que realizamos nos permite destacar, ainda, tendências da pesquisa no entendimento dos processos de aprendizagem escolar em ciências naturais. A nosso ver, colocam-se os seguintes desafios à pesquisa: 
1. Não obstante os esforços realizados nas últimas décadas, a questão da origem e evolução das crenças e teorias específicas dos estudantes permanece como objeto de investigação em aberto. As atividades de modelamento e as "técnicas de abstração" utilizadas pela ciência e por estudantes na criação de novidades são direções promissoras para a pesquisa.

2. Outro campo de estudos tem se dedicado a examinar a dinâmica de interações discursivas em sala de aula, buscando compreender esse espaço social e maneiras mais efetivas de nele intervir.

3. A investigação de mudanças nas crenças dos estudantes quanto à natureza da ciência tem sido respaldada pela importância desse tema na compreensão pública da ciência. Nesse caso, tratas-se de investigar não apenas os elementos constitutivos e a evolução dessas mudanças, mas ainda formular intervenções de ensino capazes de promovê-las efetivamente.

4. O problema da ordenação das dificuldades de aprendizagem em ciências tem sido recentemente enfocado pela pesquisa a partir de várias perspectivas teóricas. 0 reconhecimento de direções efetivas de mudanças, de modo progressivo e recursivo, pode ter importantes desdobramentos na construção de currículos, no planejamento do ensino e na avaliação da aprendizagem em ciências.

\subsection{Agradecimentos}

Agradeço os valiosos comentários e sugestões enviados pelos pareceristas.

\subsection{Referências Bibliográficas}

AGUIAR JR., O. (1999). As três formas da equilibração e a mudança conceitual: análise do material didático de um curso de eletricidade básica. Caderno Catarinense de Ensino de Física, v. 16, n. 1: 72-91.

AGUIAR JR., O. (2001). Modelo de ensino para mudanças cognitivas: um instrumento para o planejamento do ensino e a avaliação da aprendizagem em ciências. Belo Horizonte: Faculdade de Educação, UFMG. (Tese de Doutorado)

AGUIAR JR., O. \& FILOCRE, J (1999). Modelo de ensino para a mudança cognitiva: fundamentação e diretrizes de pesquisa. Ensaio - Pesquisa em Educação em Ciências, v. 1, n. 1: 47-67.

AGUIAR JR., O. \& FILOCRE, J. (2001). Repensar o ensino a partir da avaliação da aprendizagem: examinando a trajetória de um estudante em um curso de Física Térmica. Anais do III Encontro Nacional de Pesquisa em Educação em Ciências, Atibaia, SP (versão eletrônica).

ANDERSSON, B. (1986). The experiential gestalt of causation: a common core to pupils' preconceptions in science. European Journal of Science Education, v. 8, n. 2: 155-171.

ASTOLFI, J.P., PETERFALVI, B.(1993). Obstacles et construction de situations didactiques en sciences expérimentales. ASTER, n. 16: 103-141.

BORGES, A.T., GILBERT, J. (1999). Mental models of electricity. International Journal of Science Education, v. 21, n. 1: 95-117. 
BROWN, D, CLEMENT, J. (1992). Classroom teaching experiments in mechanics. In: DUIT, R., GOLDBERG,F., NIEDDERER, H. (Eds.). Research in physics learning: theoretical issues and empirical studies. Kiel: IPN, p. 380-397.

CARAVITA, S., HALLDÉN, O. (1994). Re-framing the problem of conceptual change. Learning and Instruction, v. 4: 89-111.

DE VECCHI, G. (1994). Elaborer des 'niveaux de formulation' en prenant en compte les conceptions des apprenants. In: GIORDAN, A., GIRAULT, Y., CLÉMENT, P. (Eds.). Conceptions et connaissances. Paris: Peter Lang, p. 251-264.

DÉSAUTELS,J., LAROCHELLE,M. (1990). A constructivist pedagogical strategy: the epistemological disturbance (experiment and preliminary results). In: Herget, D. (Ed.). More history and philosophy of science in science teaching. Proceedings of the First International Conference of the History and Philosophy of Science in Science Teaching. Tallahassee: Florida State University, p. 236-257.

DI SESSA, A. (1998). What changes in conceptual change? International Journal of Science Education, v. 20, n.10: 1155-1191.

DRIVER, R., ASOKO, H., LEACH, J., MORTIMER, E., SCOTT, P. (1994). Constructing scientific knolwledge in the classroom. Educational Researcher, v. 23, n. 7: 5-12.

DUSCHL, R., GITOMER, D. (1991). Epistemological perspectives on conceptual change: implications for educational practice. Journal of Ressearch in Science Teaching, v. 28, n. 9: 839-858.

DYKSTRA JR., D., BOYLE, F., MONARCH,I. (1992). Studying conceptual change in learning physics. Science Education, v. 76, n. 6: 615-652.

GUTIERREZ, R., OGBORN, J. (1992). A causal framework for analysing alternative misconceptions. International Journal of Science Education, v. 14, n. 2: 201-220.

HALBWACHS, F. (1977). Historia de la explicación en física. In: PIAGET, J. (Org.) La Explicación en las Ciencias. Barcelona: Martinez Roca.

HEWSON, P., THORLEY, R. (1989). The conditions fo conceptual change in classroom. International Journal of Science Education, v. 11, n. 5: 541-553.

HEWSON,P. (1985). Epistemological commitments in the learning of science: examples from dynamics. European Journal of Science Education, v. 7, n. 2: 163-172.

KUHN, T.S (1975). A estrutura das revoluções científicas. Trad. Beatriz V. Boeira e Nelson Boeira. São Paulo: Perspectiva. (Edição original publicada em 1962 e ampliada em 1969)

LAKATOS, I. (1979). O falseamento e a metodologia dos programas de pesquisa científica. In: LAKATOS, I., MUSGRAVE, A. (Eds.). A crítica e o desenvolvimento do conhecimento. Trad. Otávio M. Cajado. São Paulo: Edusp.

LAUDAN, L. (1984). Science and values: the aims of science and their role in scientific debate. Berckeley: University of California Press.

LEACH, J., DRIVER, R., MILLAR, R., SCOTT, P. (1997). A study of progression in learning about "the nature of science": issue of conceptualisation and methodology. International Journal of Science Education, v. 19, n. 2: 147-166.

LEMEIGMAN, G., WEIL-BARAIS, A. (1994). A developmental approach to cognitive change in mechanics. International Journal of Science Education, v. 16, n. 1: 99-120. 
MORTIMER, E. (1995). Conceptual change or conceptual profile change? Science \& Education, v. $4: 267-285$.

MORTIMER, E. (1998). Multtivoceness and Univocality in Classroom Discourse: an Example from the Theory of Matter. International Journal of Science Education, 20(1): 67-82.

MORTIMER, E. (1999). Microgenetic analysis and the dynamic of explanations in science classroom. Paper presented at the II Conference of the European Science Education Research Association, Kiel. (In press)

MORTIMER, E. (2001). Perfil conceptual: formas de pensar y hablar en las clases de ciencias. Infancia y aprendizaje, 24(4): 475-490.

NERSESSIAN, N. (1987). A cognitive-historical approach to meaning in scientific theories. In: NERSESSIAN, N. (Ed.). The process of science, Dordrecht, Netherlands: Martinus Nijhoff Publishers, p. 161-177.

NERSESSIAN, N. (1992).Constructing and instructing: the role of 'abstraction techniques' in creating and learning physics. In: DUSCHL, R., HAMILTON, R. (Eds.). Philosophy of science, cognitive psychology, and educational theory and practice. Albany: State University of New York Press, p. 48-68.

NEWMAN, D., GRIFFIN, P., COLE, M. (1989). The construction zone: working for cognitive change in school. Cambridge: Cambridge University Press.

NIEDDERER, H., SCHECKER, H. (1992). Towards an explicit description of cognitive systems for research in physics learning. In: DUIT, R., GOLDBERG,F., NIEDDERER, H. (Eds.). Research in physics learning: theoretical issues and empirical studies. Kiel: IPN, p. 74-98.

PERKINS, D., GROTZER, T. (2000). Models and moves: focusing on dimensions of causal complexity to achieve deeper scientific understanding. Paper presented at the American Educational Research Association Annual Conference, New Orleans. Available from internet: http://pzweb.harvard.edu/Research/UnderCon.htm.

PINTRICH, P., MARX, R., BOYLE, R. (1993). Beyond cold conceptual change: the role of motivational beliefs and classroom contextual factors in the process of conceptual change. Review of Educational Research, v. 63, n. 2: 167-199.

POSNER,G., STRIKE,K., HEWSON,P., HERTZOG,W. (1982). Accommodation of a scientific conception: toward a theory of conceptual change. Science Education, v. 66, n. 2: 211-227.

POZO, J. I., GÓMEZ CRESPO, M. (1998). Aprender y enseñar ciencia: del conocimiento cotidiano al conocimiento científico. Madrid: Morata.

ROZIER, S., VIENNOT, L. (1991). Students' Reasonings in Thermodynamics. International Journal of Science Education, v. 13, n. 2: 159-170.

SOLOMON, J. (1983). Learning about energy: how pupils think in two domains. European Journal of Science Education, v. 5, n. 1: 49-59.

SOLOMON, J. (1992). Getting to know about energy in school and society. London: The Falmer Press.

STRIKE,K., POSNER,G. (1992). A revisionist theory of conceptual change. In: DUSCHL, R., HAMILTON, R.(Eds.). Philosophy of science, cognitve psychology and educational theory and practice, Albany: State University of New York Press, p. 147-176. 
TIBERGHIEN, A. (1998). Analysis of teaching and learning: how differentiating and relating them. In: MEHEUT, M., REBMANN, G. Theory, methodology and results of research in science education, $4^{\text {th }}$ European Science Education Summerschool: Marly de Roi: ESERA, p. $32-45$.

VILLANI, A. (1992). Conceptual change in science and science education. Science Education, v. 76, n. 2: 223-237.

VOSNIADOU, S., IOANNIDES, C.(1998). From conceptual development to science education: a psychological point of view. International Journal of Science Education, v. 20, n. 10: 1213-1230.

VOSNIADOU, S. (1994). Capturing and modeling the process of conceptual change. Learning and Instruction, v. 4: 45-69.

WELZEL, M. (1998). The emergence of complex cognition during a unit on static electricity. International Journal of Science Education, v. 20, n. 9: 1107-1118.

WELZEL, M., AUFSCHNAITER, S. (1997). The emergence of understandings of electricity: increasing complexity of discursive and material actions. Paper presented at the 1997 NARST Conference. Available from Internet: http://www.physik.unibremen.de/physics.education/aufschnaiter/

WISER, M., CAREY, S. (1983). When heat and temperature wee one. In: GENTNER, D., STEVENS, A. (Eds.). Mental models. Hillsdale, New Jersey: Lawrence Erlbaum, p. 267-297. 


\section{Abstract \\ Conceptual (or cognitive) change in science education: critical review and new directions for research.}

Moved by the challenge to consolidate and strength science education research we need to check critically the studies done in the last 20 years about "conceptual change". This review ranges over two complementary aspects: 1 . what is the meaning and broadening of the changes in science learning? 2. What is the epistemological vector of these changes? Recognizing the diversity of approaches and theoretical frameworks used by researchers, this work points out central contributions and new challenges to researchers and science educators.

Diante do desafio de consolidar e aprofundar as pesquisas no campo da educação em ciências, coloca-se a necessidade de se fazer um balanço crítico das pesquisas realizadas nos últimos vinte anos em torno do problema da "mudança conceitual". Essa revisão abrange dois aspectos, a nosso ver complementares: 1. Qual é o sentido e alcance das mudanças que acompanham as aprendizagens em ciências; 2. Qual é o vetor epistemológico dessas mudanças? Reconhecendo a diversidade de abordagens e referenciais teóricos a que se submeteu o tema, procuramos destacar as principais contribuições e os novos desafios colocados à pesquisa e à prática educativa.

\section{Palavras chave:}

Mudança conceitual, teorias da aprendizagem, construtivismo.

Conceptual change, learning theories, constructivism.

\section{Correspondência:}

Orlando G. Aguiar Jr. - Faculdade de Educação da UFMG

Av. Antônio Carlos, 6627 - Pampulha

Belo Horizonte, MG

31.270-900

Correio eletrônico: orlando@fae.ufmg.br

\section{Identificação:}

Orlando Aguiar Jr. - Mudanças Conceituais na Educação em Ciências 